\title{
El desarrollo intelectual durante la era digital
}

\author{
Intellectual development during the digital era \\ Hermes llarraza-Lomelí \\ Servicio de Rehabilitación Cardiaca y Medicina Física. Instituto Nacional de Cardiología Ignacio Chávez. Ciudad de México, México
}

El Homo sapiens es la subespecie dominante en nuestro planeta, con más de 100,000 años de evolución continua desde que se diferenció de sus ancestros; y su desarrollo se debe gracias a complejos mecanismos de selección natural y realimentación adaptativa, donde el intelecto, la escritura y el trabajo en equipo son sus características más poderosas. Howard Gardner describió que tenemos más de 10 tipos de inteligencia a desarrollar y múltiples formas de aprendizaje han aparecido, desde el empirismo y el estudio de las huellas o vestigios dejadas por algún fenómeno (investigación) hasta la más profunda introspección reflexiva. La inquieta búsqueda por entender nuestro ser y su entorno encontró en personajes como René Descartes, Nicolás Copérnico, Galileo Galilei o Isaac Newton, la mejor estrategia de estudio hasta hoy: el método científico.

La naturaleza se nos presenta de tantas maneras que es preciso identificar las variables que indiquen con la mayor exactitud el fenómeno y sus interacciones. Es así como, en el siglo XVII, nació uno de los instrumentos de comparación más útiles para el investigador: el plano cartesiano, base de la geometría analítica. En este tipo de gráficas se puede comparar el comportamiento de la variable dependiente en relación con la independiente, de una manera más clara, y describir así su grado de asociación. El problema entonces se centró en encontrar la manera de expresar gráfica y numéricamente el comportamiento de un fenómeno natural, como el frío de un día de invierno o la fiebre de un enfermo. Para tal efecto se han utilizado diversos instrumentos con la finalidad de medir la magnitud de esas variables físicas, valores que deben compararse con un patrón previamente establecido, conocido como unidad de medida; de esta manera, la magnitud obtenida es un número que se considera, ya sea una proporción o un múltiplo de esos patrones de estandarización. Así, la unidad de longitud puede ser una pulgada, formada por la distancia cubierta por tres granos de cebada, redondos y secos, tomados del centro de la espiga y puestos punta a punta (Eduardo II de Inglaterra, siglo XIV); o puede ser el metro moderno, definido como la distancia que recorre la luz en un medio vacío durante un intervalo de $3.33564^{-09}$ segundos (Sistema Internacional de Medidas). Los instrumentos de medición han cambiado a lo largo de la historia y pueden ir del reloj solar al reloj atómico (tiempo) o desde la balanza hasta el catarómetro (masa). Con el advenimiento de la tecnología "electrónica analógica", las variables se cuantifican en valores continuos, con un alto grado de definición y rapidez que permiten al científico compararlas con claridad y precisión.

En 1936, Konrad Zuse diseñó y fabricó la primera computadora programable de la historia, una calculadora mecánica binaria operada con electricidad, la Z1. Si bien el concepto científico y filosófico de las computadoras radica en la "cibernética" propuesta por Norbert Wiener, basado en los conceptos naturalistas de

\section{Correspondencia:}

*Hermes Ilarraza-Lomelí

E-mail: hermes_ilarraza@yahoo.com
Fecha de recepción: 09-02-2020

Fecha de aceptación: 11-02-2020

DOI: 10.24875/ACM.M20000056
Disponible en internet: 00-00-2020 Arch Cardiol Mex. 2020;90(2):113-114 www.archivoscardiologia.com

1405-9940/@ 2020 Instituto Nacional de Cardiología Ignacio Chávez. Publicado por Permanyer. Este es un artículo open access bajo la licencia CC BY-NC-ND (http://creativecommons.org/licenses/by-nc-nd/4.0/). 
"teleología" de Arturo Rosenblueth y "homeostasis" de Walter Cannon, es en el código binario y el álgebra de Boole donde encontraron tecnológicamente su formato de operación. Al funcionar con electricidad, cualquier equipo electrónico de cómputo codifica la información en un código binario, que la reduce artificialmente a dos dígitos: el número "1" se asigna al paso de electricidad por un circuito y el "0" a la ausencia de flujo, conformando una unidad llamada dígito binario o bit. Así, el manejo de la información se volvió "digital", donde las variables obtenidas son de origen "discreto" y bien definido. La tecnología "electrónica digital" apareció en el mercado con gran empuje, muchas soluciones y algunos contratiempos; por un lado, nos permite capturar, almacenar y compartir la información de forma económica, fácil, rápida y en estado sólido; por el otro lado, esta información es una codificación discreta y parcializada de la realidad, producto de transducciones que también dan lugar a imprecisiones.

Este efecto se observa en la fotografía o la música, por citar dos ejemplos. Al digitalizar una imagen, la máquina traduce en " 0 y 1 " la inmensa continuidad de matices, colores y formas de la composición real y dependerá del número de bits de esa fotografía digitalizada el grado de "pixelización" y definición que adquiera. De manera análoga, al procesar la música en un formato como WAV o MP3, se pierde gran parte de la sensación multidimensional que brindan las vibraciones armónicas o parciales que son eliminadas durante el proceso de digitalización. Finalmente, la tecnología digital no es una ciencia, ni siquiera un método: es una útil herramienta para el proceso de información.

El ganador del Premio Nobel, Daniel Kahneman, señala que nuestro cerebro tiene dos fases de pensamiento: una rápida, donde la toma de decisiones es automática y se basa en la información ya aprendida; y una lenta, donde estudiamos detenidamente el problema y actuamos en un proceso de integración cognitiva más compleja. Así, la fase lenta será altamente disfuncional si la intempestiva aferencia de información nos aturde e impide el delicado proceso de reflexión y análisis, lo que dejaría el asunto en manos del azar y paralizaría nuestro desarrollo neuronal. Si bien con frecuencia tenemos que actuar con rapidez, nunca debemos hacer las cosas con prisa. Además, vivimos bajo el abrumador y omnipresente entretenimiento lúdico que impide aburrirnos, siendo la baja estimulación sensorial lo que permite al encéfalo relajarse y reflexionar.

El proceso de aprendizaje transforma nuestro encéfalo, desde el punto de vista biológico e intelectual, en un proceso dialógico, con retos y reflexión, que requiere dedicación y resiliencia. La recompensa es invaluable, ya que al adquirir el conocimiento y volvernos "sabios" solamente nos queda comprobar con humildad que no estemos equivocados. Contemplar este proceso desde la comodidad de un mundo engañosamente simple y libre de retos podría conducir a la degeneración del conocimiento científico (epistemoptosis) y a la atrofia intelectual. Nuestra esperanza radica en no cambiar simplemente al Homo digitalensis, sino transformarnos filogénicamente en Homo sapiens sapiens sapiens.

\footnotetext{
Fe de Errata

Arch Cardiol Mex. 2020;90(1):88-89.

En la página 89 , se corrobora la siguiente frase:

El paciente fue intervenido: se cerró la fístula (Fig. 2 [flecha]), y la prótesis valvular aórtica junto con el injerto tubular aórtico (que no estaba epitelizado y presentaba roturas en sus anastomosis proximal y distal como orígenes del PAA), se sustituyeron por una prótesis aórtica tubular valvulada.
} 